\title{
Education and income: which is more important for mental health?
}

\author{
R Araya, G Lewis, G Rojas, R Fritsch
}

J Epidemiol Community Health 2003;57:501-505

\begin{abstract}
Study objective: To assess which indicators of socioeconomic status are associated with an increased prevalence of common mental disorders.

Design: Cross sectional household survey.

Setting: Santiago, Chile.

Participants: Random sample of adults aged 16-65 residing in private households.

Main results: Less education (odds ratio $2.44,95 \%$ confidence intervals 1.50 to 3.97 ), a recent income decrease (odds ratio 2.14, 1.70 to 2.70), and poor housing (odds ratio 1.53, 1.05 to 2.23), were the only socioeconomic status variables that remained significantly associated with an increased prevalence of common mental disorders after adjustments. The prevalence of common mental disorders was also higher among people with manual unskilled occupations, overcrowded housing, and lower per capita income but these associations disappeared after adjustment for other explanatory and confounding variables.

Conclusions: There is a strong, inverse, and independent association between education and common mental disorders. However, income was not associated with the prevalence of common mental disorders, after adjusting for other socioeconomic variables. Similar results have been found in other Latin American studies but British studies tend to find the opposite, that income but not education is associated with common mental disorders. Understanding the impact of socioeconomic factors on mental health requires research in poor as well as rich countries.
\end{abstract}

See end of article for authors' affiliations

.....................

Correspondence to: Dr R Araya, Division of Psychiatry, University of Bristol, Cotham House, Cotham Hill, Bristol BS6 6JL, UK;

R.Araya@bris.ac.uk

Accepted for publication

5 November 2002
A ccording to the World Health Organisation much of the global health burden is attributable to the nonpsychotic and common mental disorders, such as depression and anxiety. ${ }^{1}$ Although some psychotic conditions might be more severe and burdensome on an individual basis, the volume and duration of the more common mental conditions yield a much larger aggregate burden.

Socioeconomic status is a complex concept that has been borrowed by medical researchers, often without due regard to its sociological inheritance. In epidemiology the concept is assessed indirectly using a variety of different measures with different implications for social and economic policy. Income, material possessions (or standard of living), occupational status, and education are the domains most commonly studied. Nevertheless, these measures are not equivalent and might have different meanings and represent different concepts of social position in different cultures. For instance, income changes throughout life while education remains comparatively "frozen" after early adulthood and educational attainments can have different meaning in different places. The association between relative or absolute income and health is among the most commonly reported in the scientific literature. However, several recent studies have found that this association is weakened or disappear when controlling for other socioeconomic variables, especially education..$^{2-4}$ Understanding the relation between socioeconomic status and health depends upon distinguishing these various measures and examining for independent associations with health.

A large body of scientific literature, mainly from western countries, shows that social disadvantage, especially lack of material possessions, lower income, and financial strain, are associated with common mental disorders (CMD).$^{5-9}$ However, much less is known of the socioeconomic determinants of CMD in non-western countries. Nevertheless most of the world's population live outside the western countries and it is these developing countries that experience the largest degree of socioeconomic inequality. Psychiatric household surveys from these countries rarely get published in peer reviewed journals. ${ }^{10}$ There have been a few published from Latin America over the past 20 years ${ }^{11-13}$ but because of some methodological problems, especially the lack of adjustment for potential explanatory or confounding variables no firm conclusions can be reached. Thus it is still unclear which socioeconomic factors, if any, are independently associated with an increased prevalence of CMD in Latin America and elsewhere in the developing world.

There seems to be an important gap in our knowledge about the most accurate indicators of social position and the most health sensitive socioeconomic factors across cultures. To understand better the relation between socioeconomic status and mental health, we need to carry out research in rich as well as poor countries. We carried out a large cross sectional survey of the private households of Santiago, the capital of Chile to examine which indicators of socioeconomic status are most strongly associated with the prevalence of CMD.

\section{METHODS}

\section{Participants and sampling}

This paper describes data from the Santiago Mental Disorders Survey undertaken between 1996 and 1998 in Santiago, Chile. ${ }^{14}$ The sampling involved a three stage clustered design. Households within 200 sectors from all the 35 boroughs of Santiago, capital of Chile, were randomly chosen with a probability proportional to the population size. A larger sampling fraction was needed in the most affluent boroughs to permit testing for socioeconomic differences between groups. One person per household was chosen at random. ${ }^{15}$ The sampling framework was the total adult population living in private households of Santiago, representing 3217177 people. Further details of the sampling design can be requested from the authors. 


\section{Variables}

Main outcome variable

CMD were assessed using the Revised Clinical Interview Schedule (CIS-R). ${ }^{16}$ This is a structured interview that has been fully standardised so that it can be administered by lay interviewers. People scoring 12 or above on the CIS-R total score (range 0-60) were regarded as suffering from a CMD. This threshold has been used extensively in Chile, the UK, and elsewhere. ${ }^{14} 1718$ The CIS-R in its English and Spanish versions has been used extensively in primary care and community studies with validity and reliability comparable or better than other commonly used structured interviews in mental health. ${ }^{16} 19$

\section{Socioeconomic variables}

The following socioeconomic variables were included:

\section{Education}

Subjects' own educational level was subdivided in six categories according to whether participants had completed primary education ( 8 years), secondary education ( 12 years), or higher education (more than 12 years).

\section{Monthly per capita income and recent income decrease}

The sum of net monthly salaries and other income (pensions, dividends, interests, or rents) contributed by each household member was divided by the number of residents regardless of age to generate a per capita monthly income. People were requested to consider mean income over six months before the interview. Per capita income was treated both as a continuous and categorical (quartiles and deciles) variable. Also people were asked if that house had "experienced a significant drop in income over the past six months".

\section{Quality, tenure, and overcrowding of housing}

The location, size, and quality and state of repairs of the property were assessed through visual inspection by the interviewer. Properties were classified in three categories: good, fair, and poor. Tenure of the house was divided into owned, rented, or other form of tenure such as squatter or lending. Crowding was estimated as the number of bedrooms divided by the number of people living in the premises.

\section{Occupational status of the main breadwinner}

We used the Chilean Institute of National Statistics scale with four categories: (1) Low status but stable occupation: involving employed manual non-specialised workers. (2) Low status and unstable occupation: involving casual manual nonspecialised workers. (3) Middle status occupation: involving non-manual workers, with no professional qualifications. (4) High status occupation: involving non-manual professional or business people with prestigious posts. For households where nobody was currently employed, coding was based on the last occupation of the main breadwinner.
Results were adjusted by potential confounding variables such as age and sex and other possible explanatory variables such as working status (employed, unemployed, economically inactive, and unable to work for health reasons) and the presence of a self reported physical disease in response to an open-ended question (do you suffer from any physical problem or disability at present?). Two independent physicians assessed if the physical problem would require medical attention in which case they classified this according to the bodily system involved. The self reported number of friends or relatives who could provide emotional or practical support if needed was determined with a single, open-ended question.

Several pilot studies were carried out to study the validity, reliability of the psychiatric interview and the feasibility of the procedures used..$^{16}{ }^{20}$ Local bodies granted ethical approval.

\section{Statistical analysis}

In view of the multistage random sampling design, prevalence estimates with their corresponding confidence intervals were calculated using the survey commands of the program STATA, ${ }^{21}$ which takes into account the effect of the sampling strategy (stratification and clustering) and sampling weights. The association between CMD and each socioeconomic variable was examined by calculating odd ratios and their $95 \%$ confidence intervals using logistic regression models, both before and after adjusting simultaneously for sex, age, working status, physical illness, and social support. Subsequently variables were adjusted for the potential confounding effect of the other variables representing socioeconomic status (education, income, occupational status, and quality of housing) in other logistic regression models. We tested for linear relations and interactions using likelihood ratio tests.

\section{RESULTS}

The sample framework comprised 4693 addresses, 393 of which were declared unusable because they were nonresidential or contained only residents over 65 . So effectively 4300 private households were approached. Altogether 3870 subjects were interviewed, a response rate of $90 \%$. The mean age of the sample was 35.6 (standard deviation 14.11), 53\% were women, most people were married $(55 \%)$, one third single $(34 \%)$, the rest were separated $(5 \%)$, cohabiting $(4 \%)$, and widowed $(3 \%)$. Unemployment was lower $(4.2 \%)$ than official statistics for the country $(5 \%)$. However $8.5 \%$ of the sample reported freelance work, many of whom were effectively unemployed. Forty seven per cent were fully employed, 22\% were housekeepers, $16 \%$ students, and less than $1 \%$ were permanently out of work for health reasons. Further details about the sample characteristics can be found elsewhere. ${ }^{14}$ Missing data on the main independent variables were minimal for education, income decrease, and total household income (37, 18 , and 56 respectively).

Lower income and recent income decreases were more common among less educated people (table 1). Similarly those

Table 1 Educational level, per capita income quartiles, and income decrease. Weighted percentages and $95 \%$ confidence intervals

\begin{tabular}{|c|c|c|c|c|c|c|}
\hline & \multicolumn{6}{|l|}{ Educational level } \\
\hline & $\begin{array}{l}\text { Primary incomplete } \\
\%(95 \% \mathrm{Cl})\end{array}$ & $\begin{array}{l}\text { Primary complete } \\
\%(95 \% \text { CI) }\end{array}$ & $\begin{array}{l}\text { Secondary incomplete } \\
\%(95 \% \text { CI) }\end{array}$ & $\begin{array}{l}\text { Secondary complete } \\
\%(95 \% \mathrm{CI})\end{array}$ & $\begin{array}{l}\text { Higher incomplete } \\
\%(95 \% \mathrm{Cl})\end{array}$ & $\begin{array}{l}\text { Higher complete } \\
\%(95 \% \mathrm{Cl})\end{array}$ \\
\hline \multicolumn{7}{|c|}{ Per capita income quartiles } \\
\hline Low & 77 (68 to 85$)$ & 52 (44 to 59$)$ & 29 (25 to 34$)$ & $13(11$ to 16$)$ & $8(4$ to 14$)$ & 5 (3 to 8$)$ \\
\hline Mid-low & 17 (10 to 28$)$ & 33 (25 to 42 ) & $30(26$ to 34$)$ & $24(21$ to 28$)$ & 21 (15 to 29$)$ & 18 (14 to 23 ) \\
\hline Mid-high & $5(3$ to 8$)$ & $12(8$ to 18$)$ & 25 (20 to 30$)$ & $30(26$ to 34$)$ & 34 (25 to 44$)$ & 31 (25 to 37$)$ \\
\hline High & 1 (0.4 to 2$)$ & $4(2$ to 7$)$ & 16 (13 to 19$)$ & 32 (29 to 36$)$ & 37 (29 to 47$)$ & 46 (39 to 54 ) \\
\hline \multicolumn{7}{|c|}{ Income decrease } \\
\hline Yes & 43 (36 to 50$)$ & 36 (27 to 45$)$ & 31 (27 to 35$)$ & $30(26$ to 35$)$ & 21 (16 to 28$)$ & 17 (13 to 22$)$ \\
\hline
\end{tabular}


Table 2 Association between educational levels and common mental disorders (CMD). Percentage weighted prevalence, unadjusted, and adjusted odds ratios ( $95 \%$ confidence intervals). Odds ratios refer to baseline group for each category

\begin{tabular}{|c|c|c|c|c|c|c|}
\hline Educational level & $\begin{array}{l}\text { Weighted } \\
\text { sample \% }\end{array}$ & $\begin{array}{l}\text { Prevalence \% } \\
(95 \% \mathrm{CI})\end{array}$ & $\begin{array}{l}\text { Unadjusted } \\
\text { odds ratios }\end{array}$ & Model $1^{*}$ & Model $2 \dagger$ & Model 3‡ \\
\hline Higher & 15.7 & 11.1 (8.7 to 14.1$)$ & 1.00 & 1.00 & 1.00 & 1.00 \\
\hline Secondary complete & 31.2 & 22.3 (19.3 to 25.7 ) & 2.31 (1.67 to 3.19 ) & 1.82 (1.32 to 2.52 ) & 1.63 (1.12 to 2.38 ) & 1.51 (1.04 to 2.18$)$ \\
\hline Secondary incomplete & 29.4 & 26.5 (22.5 to 30.9 ) & 2.89 (2.06 to 4.05$)$ & 2.30 (1.57 to 3.36$)$ & 1.90 (1.28 to 2.83$)$ & 1.83 (1.20 to 2.79$)$ \\
\hline Primary complete & 9.3 & 33.5 (25.2 to 42.9 ) & 4.04 (2.45 to 6.64$)$ & 2.73 (1.67 to 4.47 ) & 2.49 (1.46 to 4.24 ) & $2.16(1.26$ to 3.71$)$ \\
\hline Primary incomplete & 14.4 & 37.8 (31.7 to 44.3 ) & 4.87 (3.39 to 7.00$)$ & 3.35 (2.23 to 5.03$)$ & 2.69 (1.69 to 4.28 ) & 2.44 (1.50 to 3.97$)$ \\
\hline
\end{tabular}

*Model 1 adjusts for age, sex, physical disease, working status, and social support. †Model 2 adjusts for per capita income, income decrease, and housing variables. $¥$ Model 3 adjusts for all variables.

Table 3 Association between income, recent income decrease, occupational and working status, and common mental disorders (CMD). Percentage weighted prevalence, unadjusted, and adjusted odds ratios ( $95 \%$ confidence intervals). Odds ratios refer to baseline group for each category

\begin{tabular}{|c|c|c|c|c|c|c|}
\hline & $\begin{array}{l}\text { Weighted } \\
\text { sample \% }\end{array}$ & $\begin{array}{l}\text { Prevalence } \\
(95 \% \mathrm{CI})\end{array}$ & $\begin{array}{l}\text { Unadjusted odds } \\
\text { ratios }(95 \% \mathrm{Cl})\end{array}$ & $\begin{array}{l}\text { Model } 1 * \text { odds } \\
\text { ratios }(95 \% \mathrm{Cl} \text { ) }\end{array}$ & $\begin{array}{l}\text { Model } 2+\text { odds } \\
\text { ratios }(95 \% \text { Cl) }\end{array}$ & $\begin{array}{l}\text { Model 3f odds } \\
\text { ratios }(95 \% \mathrm{Cl})\end{array}$ \\
\hline \multicolumn{7}{|c|}{ Income per capita quartiles } \\
\hline Highest & 25.0 & 14.8 (14.7 to 14.8 ) & 1.00 & 1.00 & 1.00 & 1.00 \\
\hline Middle high & 25.5 & 23.2 (23.1 to 23 & 1.75 (1.32 to 2.31$)$ & 1.52 (1.11 to 2.08$)$ & $1.24(0.91$ to 1.70$)$ & $1.17(0.82$ to 1.66$)$ \\
\hline Middle low & 24.7 & $29.0(28.8$ to 29.2$)$ & $2.36(1.71+$ & $1.88(1.35$ & 1.3510 .9 & 1.210 .8 \\
\hline Lowest & 24.9 & $33.4(33.2$ to 33.5$)$ & $2.89(2.16$ to & $1.93(1.40$ & $1.37(0.94$ & 1.0310 .70 \\
\hline \multicolumn{7}{|l|}{ Income decrease } \\
\hline No & 69.1 & 19.3 (17.2 to 21.5$)$ & 1.00 & 1.00 & 1.00 & 1.00 \\
\hline Yes & 30.9 & $38.0(33.8$ to 42.4$)$ & 2.57 (2.08 to 3.17$)$ & 2.29 (1.84 to 2.86$)$ & $2.18(1.74$ & $2.14(1.70$ \\
\hline \multicolumn{7}{|c|}{ Occupational status of main breadwinner } \\
\hline High & 13.9 & $12.6(9.93$ to 15.9$)$ & 1.00 & 1.00 & 1.00 & 1.00 \\
\hline Mediur & 36.6 & 23.4 (19.9 to 27.4$)$ & 2.13 (1.55 to 2.93$)$ & 1.68 (1.21 to 2.33$)$ & 1.01 (0.70 to 1.47$)$ & 0.98 (0.67 to 1.43 ) \\
\hline Low stable & 39.5 & 28.6 (25.4 to 31.9 ) & 2.78 (2.03 to 3.81$)$ & 1.93 (1.37 to 2.73 ) & 0.98 (0.65 to 1.49 ) & 0.91 (0.60 to 1.40 ) \\
\hline Low unstable & 10.3 & 34.7 (28.2 to 41.8 ) & 3.67 (2.47 to 5.47$)$ & 2.47 (1.60 to 3.82$)$ & 1.22 (0.74 to 2.01$)$ & 1.18 (0.72 to 1.94$)$ \\
\hline
\end{tabular}

*Model 1 adjusts for age, sex, physical disease, working status, and social support. †Model 2 adjusts for per education, capita income, income decrease, and quality of housing. $\ddagger$ Model 3 adjusts for all variables.

people with lower income were over twice as likely to report experiencing income decreases recently than those in the highest income group (43\% (42.7 to 43.1 ) compared with $20 \%$ (19.7 to 19.9)). As expected there was some intercorrelation between the main independent variables but none of the variables was rejected from the regression models due to collinearity.

People within the lowest income quartile received about US\$50 (49 to 52) monthly whereas those in the highest income quartile earned almost 15 times more (US\$760 (677 to 844)). Both educational and income levels reported by interviewees bore striking similarity with official statistics for the areas sampled.
In an analysis adjusting for age, sex, working status, the presence of a physical disease, and perceived social support statistically significant $(\mathrm{p}<0.05)$ associations with CMD were found for the following variables: less education (table 2), lower per capita income, income decrease, lower ranked occupation of the main breadwinner (table 3), poorer housing, and overcrowding (table 4).

In the fully adjusted models, only less education (table 2), a recent income decrease (table 3 ), and housing of poorer quality (table 4$)$ remained significantly $(\mathrm{p}<0.05)$ associated with CMD after adjustment for all the other socioeconomic status variables. Adding income drop to a model that included per capita income but did not include any other socioeconomic

Table 4 Association between housing and comomn mental disorders (CMD). Percentage weighted prevalence, unadjusted, and adjusted odds ratios ( $95 \%$ confidence intervals). Odds ratios refer to baseline group for each category

\begin{tabular}{|c|c|c|c|c|c|c|}
\hline & $\begin{array}{l}\text { Weighted } \\
\text { sample \% }\end{array}$ & $\begin{array}{l}\text { Prevalence } \\
(95 \% \mathrm{CI})\end{array}$ & $\begin{array}{l}\text { Unadjusted odds } \\
\text { ratios }(95 \% \mathrm{Cl})\end{array}$ & $\begin{array}{l}\text { Model } 1 * \text { odds } \\
\text { ratios }(95 \% \mathrm{Cl})\end{array}$ & $\begin{array}{l}\text { Model } 2+\text { odds } \\
\text { ratios }(95 \% \mathrm{Cl})\end{array}$ & $\begin{array}{l}\text { Model } 3 \ddagger \text { odds } \\
\text { ratios }(95 \% \mathrm{Cl})\end{array}$ \\
\hline \multicolumn{7}{|c|}{ Quality of housing } \\
\hline Good & 27.8 & 14.6 (12.0 to 17.8 ) & 1.00 & 1.00 & 1.00 & 1.00 \\
\hline Fair & 52.5 & 27.4 (24.5 to 30.6 ) & 2.21 (1.71 to 2.84 ) & 1.78 (1.39 to 2.27$)$ & 1.39 (1.02 to 1.89 ) & 1.32 (1.00 to 1.75$)$ \\
\hline Poor & 19.7 & 33.6 (29.2 to 38.4$)$ & $2.96 \quad 2.19$ & $2.27(1.6$ & 1.57 (1.07) & 1.53 (1.05 \\
\hline \multicolumn{7}{|c|}{ Persons per bedroom } \\
\hline$\leqslant 2$ & 77.9 & 22.6 (20.4 to 25.0 ) & 1.00 & 1.00 & 1.00 & 1.00 \\
\hline $2-3$ & 17.2 & 31.7 (26.4 to 37.4$)$ & 1.58 (1.21 to 2.07 ) & 1.21 (0.93 to 1.57$)$ & 1.23 (0.92 to 1.65 ) & 1.04 (0.78 to 1.40 ) \\
\hline$>3$ & 4.9 & 41.0 (32.5 to 50.0 ) & 2.37 (1.62 to 3.48 ) & 1.95 (1.29 to 2.94$)$ & 1.50 (0.94 to 2.41$)$ & 1.42 (0.90 to 2.24$)$ \\
\hline \multicolumn{7}{|c|}{ Tenure of pro } \\
\hline Owned & 70.4 & 23.9 (20.5 to 27.7$)$ & 1.00 & 1.00 & 1.00 & 1.00 \\
\hline Rented & 14.1 & $25.2(20.1$ to 31.2$)$ & 1.07 (0.81 to 1.42 ) & $1.03(0.76$ to 1.40$)$ & 1.27 (0.96 to 1.68$)$ & $1.13(0.83$ to 1.55$)$ \\
\hline Other & 15.5 & 30.1 (23.8 to 37.3$)$ & 1.37 (1.03 to 1.83 ) & $1.16(0.86$ to 1.56$)$ & 1.14 (0.84 to 1.55 ) & 0.99 (0.73 to 1.32 ) \\
\hline
\end{tabular}

* Model 1 adjusts for age, sex, physical disease, working status, and social support. †Model 2 adjusts for per education, capita income, income decrease, and quality of housing. $\ddagger$ Model 3 adjusts for all variables. 
variables did not eliminate the statistically significant association found between income and CMD. However, it was with the addition of other socioeconomic variables to the same model that this statistically significant association between income and CMD disappeared. Different analyses were carried out using per capita income grouped in 10,6, and 4 categories and education in 6,5, and 4 categories. Virtually the same pattern of results emerged from these analyses with education, income drop, and poorer housing quality showing the only statistically significant associations $(p<0.05)$ with CMD.

We found no statistically significant interactions $(p<0.05)$ between education, income, and income decrease.

\section{DISCUSSION}

In keeping with most previous studies from developed as well as developing countries we found a higher prevalence of CMD among the most socially disadvantaged groups defined according to a variety of socioeconomic indicators. Nevertheless, only a recent income drop, lower level of education, and poorer housing quality showed independent and statistically significant associations with an increased prevalence of CMD after adjusting for other explanatory variables. In contrast with findings from other studies in Europe and America, income was not associated with the prevalence of CMD after adjusting for other socioeconomic variables. Some factors, such as acute financial strain, might have a more universal impact on mental health ${ }^{5}$; whereas others, such as income or education, might be more country specific. The cross sectional design of this study precludes us from reaching any conclusions about the direction of causality.

Chile is one of the 10 countries in the world with the most unequal distribution of income. Within these 10 countries, Chile has the smallest proportion of people living on less than US $\$ 1 /$ day and one of the highest levels of education. ${ }^{22}$ Over the past four decades successive governments have declared education is essential to eradicate poverty. Parents have to ensure their children receive at least eight years of basic education, which is free in state schools. Thus illiteracy is fairly uncommon, especially among younger generations. Nevertheless access to higher education is increasingly more difficult for the poor. Poor families incur large debts to pay for a university degree that no longer gives certainty of a high paid job in the future.

Our results showed a robust, dose-response, and independent inverse association between education and CMD. Other Latin America studies had shown similar findings but reaching conclusions was limited because of methodological problems, such as the use of questionnaires rather than interviews, limitations in the sampling, poor response rates, and, most importantly, unadjusted results. ${ }^{1323}$ With this study most of these problems were successfully overcome. A British study, which used similar methodology to ours, did not find a statistically significant association between education and CMD after adjustment for other socioeconomic measures. ${ }^{7}$ It is unclear why education could be more closely associated with the prevalence of CMD in a poor Latin American country rather than in the UK. The lack of association between CMD and education in the British sample could have arisen because most people achieved a higher level of education and the sample might have been too homogeneous to detect any differences. However, this did not seem to be the case, the British sample had a reasonable spread among categories denoting different educational levels according to qualifications achieved (no qualifications, GCSE, and A levels). The educational level in the Chilean study was measured according to whether people had completed primary, secondary, or higher education. Thus the way we estimated educational achievement was different but we think both represented a similar concept, namely the educational level achieved by people. A number of explanations could account for this association between CMD and education in poorer Latin American countries.

Poor education could be a marker for childhood adversity, which could hypothetically be more common among Chileans and play a fundamental part in determining susceptibility to depression or other diseases later in life. ${ }^{24}{ }^{25}$ It would have been useful to have more precise information on early life circumstances but this kind of information when collected retrospectively is usually affected by a strong recall bias. Thus, a longitudinal design would be required to test this hypothesis. Education could be perceived or objectively represent a more sensitive indicator of lack of opportunity or low social position in developing rather than developed countries. It is probable that educational attainment might mean different things in different places. For instance, governments in third world countries present education as the most important requirement to avoid poverty. Consequently people with less education might feel socially trapped and helpless; contributing to the emergence of psychiatric disorders according to some psychological theories. ${ }^{26}$ Finally less educated people might show a response bias when reporting psychological symptoms. There is some evidence in this respect but mainly related to the use of self administered questionnaire ${ }^{27}$ rather than interviews such as the one used in our study. At present we do not know which of these or indeed any other explanations can provide the best answer to this puzzle.

We found a robust statistically significant association between a "recent income decrease" and an increased prevalence of CMD before and after adjustments. The association between financial strain and CMD seems to be more consistent across countries. ${ }^{82}$ We had no way of confirming that the people had actually experienced a decrease in income and we also assumed this implied some strain. Also the reporting of a negative event, such as a decrease in income, is possibly more likely among those people suffering from a CMD. We expected that unemployment or being unable to work for health reasons could have greatly confounded the association between "a recent income decrease" and CMD but this did not seem to be the case. It is possible that the effect of being out of work on income could have been somehow diluted by the contribution made by other members to the household budget. Our measure of income per capita was the sum of all the contributions made by household members divided by the total number of people living in those premises. It is important to realise that an income decrease might also arise from other sources such as reduction in salaries or a decrease in freelance work.

We found a statistically significant association between income and CMD, but this effect disappeared after adjusting for other socioeconomic variables. In Brazil, another middle income country with great inequalities, the association between income and CMD was also weak after adjustment for other socioeconomic variables. ${ }^{13}{ }^{23}$ In contrast, studies in the UK and USA found clear and significant independent associations between income and CMD after adjustment. ${ }^{8}{ }^{9}$ It is possible that those people with higher income could have underreported their income and this would have attenuated the differences in the prevalence of CMD between various income groups. However, our measures of income and education showed great resemblance with the official government statistics and we have no other reason to believe that a large measuring bias might have been introduced. We used different ways of grouping the income and education variables but our results remained unchanged. Again adjusting for "working status" did not influence greatly the association between income and CMD, even though lower income usually increases psychological distress and it is more common among the unemployed or unable to work for other reasons. The absence of a large confounding effect of "working status" on the association between income and CMD can be partly explained by the small proportion of people who were unemployed or 
unable to work. Furthermore, we tested for interactions between income and income decrease with "working status" but none were statistically significant $(p<0.05)$. Nevertheless, the association of material factors, wealth, and CMD seems to have been captured better by the quality of the housing, a variable that might represent a more stable picture of wealth than income.

Far too often research findings on the association between health and socioeconomic indicators in the western world are extrapolated to poorer countries as if no important differences exist. However, these socioeconomic indicators represent complex concepts, subject to cultural as well as social influences. We invite readers to be more cautious when using these socioeconomic indicators outside the western world. Understanding the impact of socioeconomic factors on mental health, or indeed any other health outcome, requires research in poor as well as rich countries.

\section{ACKNOWLEDGEMENTS}

We would like to thank all the interviewers who participated in this study. Also our thanks to Dr David Gunnell, Social Medicine Department, University of Bristol, for reading this paper and providing some useful comments.

\section{Authors' affiliations}

R Araya, G Lewis, University of Bristol, Division of Psychiatry, Bristol, UK G Rojas, R Fritsch, Clinica Psiquiatrica, Facultad de Medicina, Universidad de Chile, Santiago, Chile

Funding: This study was funded by the European Community (EC).

Conflicts of interest: none.

\section{REFERENCES}

1 Murray C, Lopez A. Alternative projections of mortality and disability by cause 1900-2020: Global Burden of Disease Study. Lancet 1997;349: 1498-504.

2 Davey Smith G, Hart C, Hole D. Education and occupational social class: which is the more important indicator of mortality risk? J Epidemiol Community Health 1998;52:153-60.

3 Ellison G. How robust is the association between income distribution and health? J Epidemiol Community Health 1998;52:694.

4 Muller A. Education, income, and mortality: a multiple regression analysis. BN 2002;324: 1-4

5 Reading R. Debt, social disadvantage, and maternal depression. Soc Sci Med 2000;53:454
6 Kessler RC, McGonagle KA, Zhao S, et al. Lifetime and 12-month prevalence of DSM-III-R psychiatric disorders in the United States. Arch Gen Psychiatry 1994;51:8-19.

7 Lewis G, Bebbington P, Brugha T, et al. Socio-economic status, standard of living and neurotic disorder. Lancet 1998;352:605-9.

8 Weich S, Lewis G. Poverty, unemployment and the common mental disorders: a population based cohort study. BMU 1998;317:115-19.

9 Khan RS, Wise PH, Kennedy BP, et al. State income inequality, household income, and maternal mental and physical health: cross sectional national survey. BM 2000;321:1311-15.

10 Patel V, Sumathipala A. International representation in psychiatric literature: survey of six leading journals. Br J Psychiatry 2001:178:406-9.

11 Canino GJ, Bird HR, Shrout PE. The prevalence of specific psychiatric disorders in Puerto Rico. Arch Gen Psychiatry 1987;44:727-35.

12 Almeida-Filho N, Mari J, Coutinho E, et al. Brazilian Multi-centric study of psychiatric morbidity. Br J Psychiatry 1997;171:524-9.

13 Ludemir A, Lewis G. Links between social class and common mental disorders in northeast Brazil. Soc Psychiatry Psychiatr Epidemiol 2001; 36:101-7.

14 Araya R, Rojas G, Fritsch R, et al. Common mental disorders in Santiago, Chile. Prevalence and socio-demographic correlates. Br J Psychiatry 2001;178:228-33.

15 Kish L. Survey sampling. London: Wiley, 1965.

16 Lewis G, Pelosi AJ, Araya R, et al. Measuring psychiatric disorder in the community: a standardised assessment for use by lay interviewers. Psychol Med 1992; 22:465-86.

17 Jenkins R, Lewis G, Bebbington P, et al. The National Psychiatric Morbidity Surveys of Great Britain: Initial findings from the Household Survey. Psychol Med 1997; 27:775-90.

18 Jacob KS, Everitt BS, Patel V, et al. The comparison of latent trait variable models of non-psychotic psychiatric morbidity in four culturally diverse populations. Psychol Med 1998;28:145-52

19 Andrews G, Peters L. The psychometric properties of the Composite International Diagnostic Interview. Soc Psychiatry Psychiatr Epidemiol 1998;33:80-8.

20 Araya R, Wynn R, Leonard R, et al. Psychiatric morbidity, detection by physicians, and frequency of consultation in primary care. Br J Psychiatry 1994; 165:530-3

21 STATA. STATA. Version 6.0. College Station, TX: STATA, 1999.

22 World Bank. World Development Report 2000/2001. Attacking poverty. New York: Oxford University Press, 2001.

23 Blue I. Individual and contextual effects on mental health status in Sao Paulo, Brazil. Revista Brasileira de Psiquiatria 2000;22:1 16-23.

24 Wise LA, Zierler S, Krieger N, et al. Adult onset of major depressive disorder in relation to early life violent victimisation: a case-control study. Lancet 2001;358:881-7.

25 Veijola J, Puuka P, Lethinen V. Sex differences in the association between childhood experiences and adult depression. Psychol Med 1998;28:21-8

26 Gilbert P. Depression: the evolution of powerlessness. Hove: Erlbaum, 1992.

27 Lewis G, Araya R. Is the General Health Questionnaire (12 item) a culturally biased measure of psychiatric disorder? Soc Psychiatry Psychiatr Epidemiol 1995;30:20-5.

28 Patel V, Araya R, Ludemir A, et al. Women, poverty and common mental disorders in four restructuring societies. Soc Sci Med 1999;49:1461-71. 